\title{
The System of Radiation Dose Assessment and Dose Conversion Coefficients in the ICRP and FGR
}

\author{
Sora Kim, Byung-II Min, Kihyun Park, Byung-Mo Yang, Kyung-Suk Suh* \\ Nuclear Environmental Safety Research Division, Korea Atomic Energy Research Institute, Daejeon, Korea
}

\section{Note}

Received July 18, 2016

Revision August 26, 2016

Accepted September 30, 2016

Corresponding author: Kyung-Suk Suh

Korea Atomic Energy Research Institute, 989-111 Daedeok-daero, Yuseong-gu,

Daejeon 34057, Korea

Tel: $+82-42-868-4788$,

Fax: $+82-42-868-8943$

E-mail: kssuh@kaeri.re.kr

This is an Open-Access article distributed under the terms of the Creative Commons Attribution NonCommercial License (http://creativecommons.org/ licenses/by-nc/4.0) which permits unrestricted noncommercial use, distribution, and reproduction in any medium, provided the original work is properly cited.

Copyright $\odot 2016$ The Korean Association for Radiation Protection

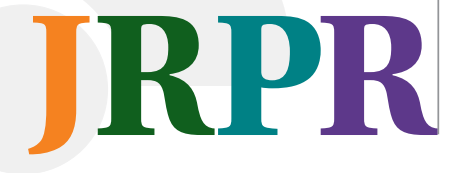

Background: The International Commission on Radiological Protection (ICRP) recommendations and the Federal Guidance Report (FGR) published by the U.S. Environmental Protection Agency (EPA) have been widely applied worldwide in the fields of radiation protection and dose assessment. The dose conversion coefficients of the ICRP and FGR are widely used for assessing exposure doses. However, before the coefficients are used, the user must thoroughly understand the derivation process of the coefficients to ensure that they are used appropriately in the evaluation.

Materials and Methods: The ICRP provides recommendations to regulatory and advisory agencies, mainly in the form of guidance on the fundamental principles on which appropriate radiological protection can be based. The FGR provides federal and state agencies with technical information to assist their implementation of radiation protection programs for the U.S. population. The system of radiation dose assessment and dose conversion coefficients in the ICRP and FGR is reviewed in this study.

Results and Discussion: A thorough understanding of their background is essential for the proper use of dose conversion coefficients. The FGR dose assessment system was strongly influenced by the ICRP and the U.S. National Council on Radiation Protection and Measurements (NCRP), and is hence consistent with those recommendations. Moreover, the ICRP and FGR both used the scientific data reported by Biological Effects of Ionizing Radiation (BEIR) and United Nations Scientific Committee on the Effects of Atomic Radiation (UNSCEAR) as their primary source of information. The difference between the ICRP and FGR lies in the fact that the ICRP utilized information regarding a population of diverse races, whereas the FGR utilized data on the American population, as its goal was to provide guidelines for radiological protection in the US.

Conclusion: The contents of this study are expected to be utilized as basic research material in the areas of radiation protection and dose assessment.

Keywords: Radiation protection, ICRP, FGR, Dose (conversion) coefficient, External exposure, Internal exposure

\section{Introduction}

The advisory materials of the International Commission on Radiological Protection (ICRP) and the Federal Guidance Report (FGR) of the Environmental Protection Agency (EPA) have been widely used in radiation protection and dosimetry due to their high reliability.

The ICRP provides suasion and guidelines regarding risk protection from ionizing radiation produced from natural and artificial radiation sources that are widely used in 
the industrial sector. Starting from publications regarding the protection of medical personnel in 1928, the ICRP has produced numerous publications, and in 1959 published ICRP publication 1, the first report in the current publication format. Since then, as research regarding the effects of ionizing radiation on the human body advanced, the basic system of radiation protection has been outlined in several publications. The main recommendations were published in ICRP 6 (1964), ICRP 9 (1966), ICRP 26 (1977), ICRP 60 (1991), and ICRP 103 (2007), while other recommendations dealing with more specific areas were published as supporting publications [1]. The basic system of radiological protection, derivation of dose (conversion) coefficients, methodology, applied model, and data produced by the ICRP is described in sections 1-3.

The FGR of the EPA was created as a guide for the federal agencies of the United States that were developing radiological protection regulations and standards to protect the citizens of the United States from both the direct and indirect health effects of radiation. The FGR consists of two parts: Presidential Guidance, which provides basic concepts of radiological protection and policy recommendations for the public and for workers, and a technical report that contains supplemental information for the Presidential Guidance and other information regarding recent technology and scientific developments used to evaluate radiation dose and risk levels. ${ }^{1)}$ The first federal radiological protection guidebook containing the basic concepts of protection for the public and workers was published in 1960. Since the guidebook was heavily influenced by the ICRP and the National Council on Radiation Protection and measurements (NCRP), it is consistent with the recommendations of the ICRP and NCRP [2]. From the mid-1980s, the EPA published a series of federal guidance documents to provide federal agencies with technical information to support radiological protection programs. The details regarding the dose assessment system and dose coefficients are provided in sections 4-5.

The dose conversion coefficients provided by the ICRP and FGR are commonly used in dose assessments. However, before the coefficients are used, the user must thoroughly understand the derivation process of the coefficients to ensure that they are used appropriately in the evaluation. Hence, this paper presents a review of the radiological protection and dose assessment system of the ICRP and FGR.

\section{Materials and Methods}

This paper presents an overall analysis of the radiological protection and dose assessment system by reviewing all relevant ICRP publications and the most recent FGR. This review includes the major components of these documents, such as the quantity and basics of radiological protection and information regarding the dose conversion coefficients of internal and external dose assessments for the public and workers, along with the applied model and data for the derivation of the dose conversion coefficient. Concepts related to radiological protection systems, changes in the applied model and the data used for the derivation of the dose conversion coefficient, and the criteria that will be modified in the near future are also addressed.

\section{Results and Discussion}

\section{Radiological protection system recommended by the ICRP}

To achieve the goal of radiological protection for occupations at risk of radiation exposure, ICRP 26 (1977) introduced the concept of a 'system of dose limitation' alongside 3 fundamental laws consisting of the justification of the action, optimization of protection, and personal dose limit. Additionally, a new unit of dosage called the effective dose equivalent was also implemented, thereby quantifying the probabilistic effects of radiation for the first time [3]. Although only controllable sources were included in the system of dose limitation, the ICRP 60 (1991) guidelines expanded the scope to include uncontrollable sources, creating an expanded concept known as the system of radiological protection. The system of radiological protection also included an intervention procedure to reduce people's exposure [4]. Moreover, a personal dose constraint value was implemented to emphasize the optimization of protection. The recommendation of ICRP 103 (2007) maintained the system of radiological protection from ICRP 60 (1991), and only modified some recommendations based on newly discovered scientific information. Furthermore, it also discarded the method of approach based on action and intervention, and implemented an approach based on planned, emergency, and existing exposure situations. A reference level and dose constraint were implemented to optimize protection for all exposure situa-

1) Environmental Protection Agency web site. https://www.epa.gov/radiation/federal-guidance-radiation-protection. accessed 7 June 2016. 
tions, and the individual dose limits were retained from the effective and equivalent doses presented in the sources outlined in the planned exposure situations. Finally, the radiological protection range was also extended to include the environment [1].

\section{Dose (conversion) coefficient of the ICRP}

The ICRP uses the term 'dose conversion coefficient' for external exposure, and uses 'dose coefficient' for internal exposure. A computational phantom is used for the evaluation of the dose conversion coefficient, while a biokinetic model of radionuclides along with anatomical and physiological data are additionally required for the evaluation of the dose coefficient [1]. This section analyzes and organizes information regarding the applied model and data used during the coefficient calculation, along with the information and updates provided in the publications.

\section{1) Internal exposure dose coefficient}

The dose coefficient for internal exposure is assigned by age group (3-month-old infants; children of 1, 5, 10, and $15 \mathrm{yr}$ of age; and adults) for the public and assigned to adults for occupational exposure. Suggestions made in ICRP 68 (1994) and ICRP 72 (1996) organized and added to the dose coefficient published in previous publications. Additionally, the internal exposure dose coefficient published in those 2 articles were reproduced and recommended in ICRP 119 (2012).

\section{(1) Dose coefficient for the intake of radionuclides by the public}

In ICRP 30 (1969), a dose assessment model and biokinetic data were used to establish a secondary limit (annual limits on intake) for the management of radionuclide intake (inhalation and ingestion) by workers. However, the use of the biokinetic data of ICRP 30 (1969) in establishing a limit on the intake of radionuclides and dose equivalent for the public is not recommended. To develop a dose coefficient for the public, an understanding of the age dependency of the biokinetics of radionuclides, anatomical data, and biophysical data were necessary. Furthermore, information regarding the effect of radionuclides on embryos and fetuses was also required. The need for the derivation of a dose coefficient usable on an international scale became even more apparent after the Chernobyl disaster [5].

In 1987, the ICRP formed a Task Group on Age-Dependent Dosimetry to conduct dose assessment in various age groups among members of the public and to develop a biokinetic model for the distribution, residual durations, and release of radionuclides within the body. Later, this group was combined with the Task Group on Dose Calculations to form the Task Group on Internal Dosimetry, and prepared ICRP 56 (1989), 67 (1993), 69 (1995), and 71 (1995) to create a dose coefficient for the public [6]. ICRP 56 (1989) is based on the recommendations of ICRP 26 (1977), while ICRP 67 (1993), 69 (1995), and 71 (1995) are based on the recommendations of ICRP 60 (1991). ICRP 56 (1989), 67 (1993), and 69 (1995) contain the deposit-equivalent dose coefficient and committed effective dose coefficient for ingestion by age group, while ICRP 71 (1995) contains the same, but for inhalation.

Although ICRP 56 (1989) also included a dose coefficient for inhalation, this value was just a temporary placeholder calculated from ICRP 30 (1979), which did not consider variation among age groups. This was because a publication regarding a modified human inhalation model that considered age as a variable was planned for the future [5]. Of the 4 publications that contained the dose coefficient by age group for the intake of radionuclides, the publication numbers of those that contain information on the types of nuclides, data, and applied evaluation model are shown in Table 1.

In ICRP 72 (1996), the age-dependent committed effective dose coefficients for the intake of the radioisotopes of the 31 nuclides listed in the 4 publications were organized and modified. It also used the biokinetic model from the ICRP 30 series (ICRP part 1-4) developed for the evaluation of workers to produce committed effective dose coefficients for the radioisotopes of the 60 nuclides that were evaluated, but it did not contain deposit-equivalent dose coefficients for tissues or organs [6]. Information regarding the publications that contain the dose coefficients for the intake of radionuclides by the public is shown in Figure 1. Furthermore, information regarding the evaluation model and data applied during the calculation of the coefficients is provided in section 3.

(2) Dose coefficient for the intake of radionuclides by workers: ICRP Publication 68 (1994)

The committed effective dose coefficient based on the intake of radionuclides (approximately 800 radionuclides) by workers was presented in ICRP 68 (1994). Radon and daughter radionuclides that have short half-lives were not dealt with in ICRP 68 (1994), and were separately managed in ICRP 65 (1993). The radiation and tissue weighting factors presented in ICRP 60 (1991) were used and the radionuclide 
Table 1. Summary of ICRP Publications on Dose Coefficients for Members of the Public for the Intake of Radionuclides [6]

\begin{tabular}{|c|c|c|c|c|}
\hline \multirow{2}{*}{ ICRP Publication } & \multicolumn{4}{|c|}{ Publications on age-dependent dose coefficients } \\
\hline & ICRP 56 (1989) & ICRP 67 (1993) & ICRP 69 (1995) & ICRP 71 (1995) \\
\hline Selected radioisotopes & $\begin{array}{r}\mathrm{H}, \mathrm{C}, \mathrm{Sr}, \mathrm{Zr}, \mathrm{Nb}, \mathrm{Ru}, \mathrm{I} \\
\mathrm{Cs}, \mathrm{Ce}, \mathrm{Pu}, \mathrm{Am}, \mathrm{Np}\end{array}$ & $\begin{array}{l}\text { S, Co, Ni, Zn, Mo, Tc, Ag, Te, } \\
\text { Ba, Pb, Po, Ra (model up- } \\
\text { dates for Sr, Pu, Am, Np) }\end{array}$ & $\mathrm{Fe}, \mathrm{Sb}, \mathrm{Se}, \mathrm{Th}, \mathrm{U}$ & $\begin{array}{l}\mathrm{H}, \mathrm{C}, \mathrm{Sr}, \mathrm{Zr}, \mathrm{Nb}, \mathrm{Ru}, \mathrm{l}, \mathrm{Cs}, \mathrm{Ce}, \\
\mathrm{Pu}, \mathrm{Am}, \mathrm{Np}, \mathrm{S}, \mathrm{Co} \mathrm{Ni} \mathrm{Zn}, \mathrm{Mo}, \\
\text { Tc, Ag, Te, Ba, Pb, Po, Ra, Fe, } \\
\text { Sb, Se, Th, U, Ca, Cm }\end{array}$ \\
\hline Ingestion dose coefficients & $t^{*}$ & + & + & - \\
\hline Gastrointestinal tract model & ICRP 30 & ICRP 30 & ICRP 30 & ICRP 30 \\
\hline Inhalation dose coefficients & + & - & - & + \\
\hline Respiratory tract model & ICRP 30 & $\mathrm{n} / \mathrm{a}^{\dagger}$ & $\mathrm{n} / \mathrm{a}$ & ICRP 66 \\
\hline Tissue weighting factors & ICRP 26 & ICRP 60 & ICRP 60 & ICRP 60 \\
\hline Radiation weighting factors & ICRP 26 & ICRP 60 & ICRP 60 & ICRP 60 \\
\hline Nuclear decay data & ICRP 38 & ICRP 38 & ICRP 38 & ICRP 38 \\
\hline
\end{tabular}

${ }^{*}+/-$, Dose coefficients given or not given in the report.

${ }^{\dagger} \mathrm{n} / \mathrm{a}$, not applicable.

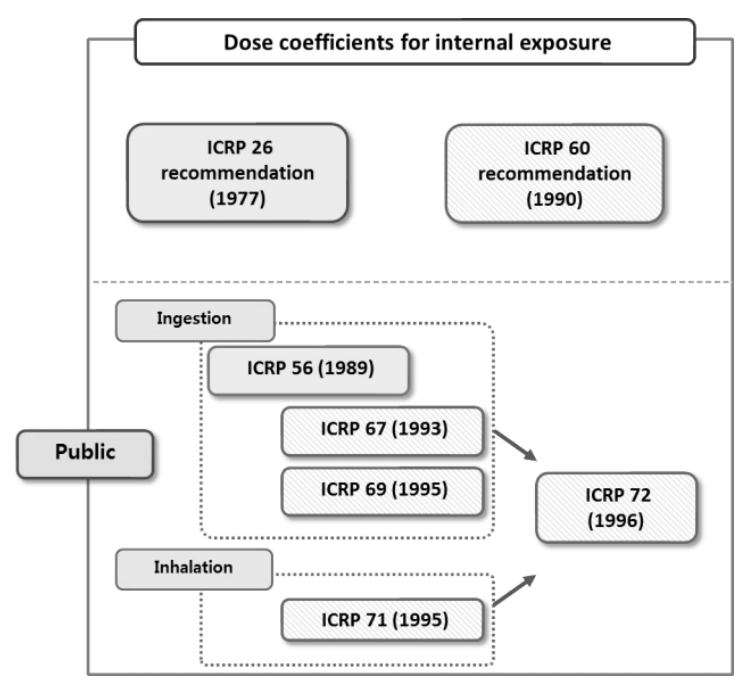

Fig. 1. International Commission on Radiological Protection (ICRP) publications of dose coefficients for members of the public from intake of radionuclides.

decay data were based on ICRP 38 (1983). The human respiratory tract model (HRTM), which was an update in ICRP 66 (1994) of the ICRP 30 (1979) model designed for workers, was used for the respiratory model. During the calculation of the dose coefficient for the inhalation of radionuclides by workers, the standard was an adult male conducting light work while breathing through the nose. A $5 \mu$ m activity median aerodynamic diameter is recommended for occupational exposure [7]. The human gastrointestinal tract model was used as the gastrointestinal tract model in ICRP 30 (1979). The model from the ICRP 30 series (parts 1-4) was used as the biokinetic model required to evaluate the transport of the radionuclide within the body, except for nuclides additionally updated in ICRP 56 (1989), 67 (1993), and 69 (1995) [8].
(3) ICRP Publication 119 (2012)

ICRP 119 (2012) provided recalculated values of the dose coefficient for the intake of radionuclides by workers and members of the public from ICRP 68 (1994) and ICRP 72 (1996), along with the dose conversion coefficient for the radiological protection of workers from external exposure published in ICRP 74 (1996). These values in ICRP 119 (2012) were reproduced based on the recommendation of ICRP 60 (1991).

Although the internal exposure dose coefficients regarding inhalation and intake published in ICRP 119 (2012) were organized based on the values published in ICRP 68 (1994) and 72 (1996), the values published in these 2 publications are slightly different. In the process of preparing the ICRP CD1 (1996; Database of dose coefficients: workers and members of the public), supporting ICRP publication 72, minor errors were found in the dose coefficients of ${ }^{232} \mathrm{~Pa}$ and ${ }^{231} \mathrm{U}$, and the $\mathrm{CD} 1$ database corrected the errors. The modified effective dose coefficients for the inhalation of ${ }^{228} \mathrm{Th}$ and ${ }^{231} \mathrm{U}$, along with the effective dose coefficients for ingestion of ${ }^{228} \mathrm{Th},{ }^{232} \mathrm{~Pa}$, and ${ }^{231} \mathrm{U}$ were published in ICRP 119 (2012). ICRP 68 (1994) and 72 (1996) used the nuclide decay data published in ICRP 38 (1983) in its calculations. In the physical data used during the process of preparing ICRP 38 (1983), there was a lack of information regarding the ground and excited state of some of the radionuclides. For these radionuclides, a temporary value was calculated based on the physical half-lives of the nuclides for the creation of the CD1 database. Subsequently, the radionuclide decay data from ICRP 38 (1983) was updated in ICRP 107 (2008), and the correct information regarding the missing radionuclides was provided. The radionuclide decay data published in ICRP 107 (2008) were applied in ICRP 119 (2012). 


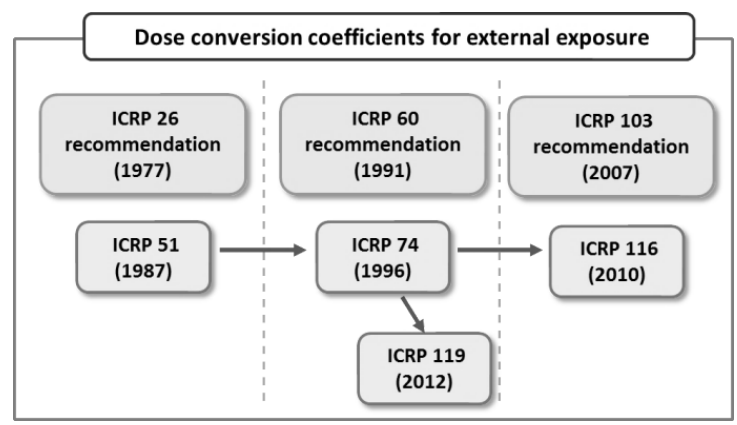

Fig. 2. International Commission on Radiological Protection (ICRP) publications of dose conversion coefficients for external exposure.

A new internal exposure dose coefficient based on the ICRP 103 (2007) recommendations is currently in progress, and will likely require some more years. ICRP 119 (2012) is a compilation of values calculated prior to the system recommended in ICRP 103 (2007) [9].

\section{2) External exposure dose coefficient}

The ICRP publications that deal with the external exposure dose coefficient are ICRP 51 (1987), 74 (1996), 116 (2010), and 119 (2012). Figure 2 shows a summary of the main recommendations serving as the basis for each publication and their relationships with one another. Because most countries currently apply the dose assessment system derived from the recommendations of ICRP 60 (1991), ICRP 74, and 116 (2010), which are based on the recommendations of ICRP 60 (1991) and ICRP 103 (2007) respectively, will be discussed in this section, as summarized in Figure 2.

\section{(1) ICRP Publication 74 (1996)}

After the publication of ICRP 26 (1977), the International Commission on Radiation Units and Measurements (ICRU) developed quantifiable operational quantities to supplement the radiation quantities on the human body specified by the ICRP. Subsequently, in the ICRP 60 (1991) recommendations, some details regarding radiological protection were modified. As a new main recommendation was announced, a review of much of the basic information regarding protection from internal and external exposure was required. To assess the suitability of existing operational quantities in expressing protection-related quantities, a collaborative work group between the ICRP and ICRU was created. Using the research of the collaborative work group as a foundation, ICRP 74 (1996) ('Conversion Coefficients for Use in Radiological Protection Against External Radiation') was published.
With limited exceptions, the evaluation indicated that the existing operational quantities were still usable, with even the exceptions indicating only slight differences in the radiological protection quantities. This report contains evaluative data regarding conversion coefficients for radiological protection and recommendations for operational quantities for external radiation from single-energy photons, neutrons, and electron beams in specific exposure situations. ICRP and ICRU did not officially recommend a phantom for more than $30 \mathrm{yr}$; the external radiation dose conversion coefficients in ICRP 74 (1996) were evaluated with mathematical phantoms (medical internal radiation dose [MIRD] phantoms) using the reference man human anatomical data contained in ICRP 23 (1965) and ICRU 48. The applied model, radiation type, energy range, irradiation exposure geometry, and calculation code (Monte Carlo radiation transport code) used in the evaluation of the dose conversion coefficient are provided in Table 2.

ICRP 74 (1996) reviewed the relationship between the effective dose and operational dose quantities of an idealized irradiation exposure geometry. This publication did not deal with partial exposure of the human body, and hence no recommended conversion coefficients exist for such situations [10].

\section{(2) ICRP Publication 119 (2012)}

As indicated above, ICRP 119 (2012) contains a partial summary of the ICRP 74 (1996) dose conversion coefficients used for radiological protection from external exposure in the workplace. ICRP 119 (2012) provides a compilation of values from the ICRP 60 (1991) recommended assessment.

\section{(3) ICRP Publication 116 (2010)}

After a new reference man was defined for male and female adults (ICRP 89 [2002]) and the dose assessment system was modified (ICRP 103 [2007]), new conversion coefficients to replace those from ICRP 74 (1996) were evaluated and published in ICRP 116 (2010). Along with the ICRP 74 (1996) update, ICRP 116 (2010) extended the number of radiation types and energy ranges evaluated (Table 2).

The external radiation dose conversion coefficient in ICRP 116 (2010) was evaluated using the computational phantoms from ICRP 110 (2009), which utilized the reference man for male and female adults and the anatomical data of the human body presented in ICRP 89 (2002). ICRP 116 (2010) was the first ICRP publication to provide coefficients evaluated by the application of a phantom, which was developed based 
Table 2. Summary of Applied Model and Data for Calculating Dose Conversion Coefficients of External Exposure in ICRP Publications 74 (1996) and $116(2010)[10,11]$

\begin{tabular}{|c|c|c|}
\hline & ICRP 74 (1996) & ICRP 116 (2010) \\
\hline Radiation and tissue weighting factor & ICRP 60 & ICRP 103 \\
\hline $\begin{array}{l}\text { Reference man (basic anatomical and } \\
\text { physiological data) }\end{array}$ & ICRP 23 (reference man) & ICRP 89 (adult reference female and male) \\
\hline Reference computational phantom & No officially recommended phantom & ICRP 110 (voxel phantom) \\
\hline Nuclear decay data (physical data) & ICRP 38 & ICRP 107 \\
\hline Radiation types and energy ranges & $\begin{array}{l}\text { Photons }(\sim 10 \mathrm{MeV}) \\
\text { Neutrons }(\sim 180 \mathrm{MeV}) \\
\text { Electrons }(\sim 10 \mathrm{MeV})\end{array}$ & $\begin{array}{l}\text { Photons }(\sim 10 \mathrm{GeV}) \\
\text { Neutrons }(\sim 10 \mathrm{GeV}) \\
\text { Electrons and positrons } \\
(\sim 10 \mathrm{GeV}) \\
\text { Proton }(\sim 10 \mathrm{GeV}) \\
\text { Negative and positive pions }(\sim 200 \mathrm{GeV}) \\
\text { Negative and positive muons }(\sim 10 \mathrm{GeV}) \\
\text { Helium ions }(\sim 10 \mathrm{GeV} / \mathrm{u})\end{array}$ \\
\hline Irradiation geometry & AP, PA, LLAT, RLAT, ROT, ISO & AP, PA, LLAT, RLAT, ROT, ISO \\
\hline Monte Carlo transport codes & $\begin{array}{l}\text { DEEP, EGS4, ETRAN, FANEUT, GSF, HADRON, } \\
\text { HL-PH, JEUNESSE, LAHET, MCNP, MORSE-CG, PTB/ } \\
\text { BG, SAM-CE }\end{array}$ & $\begin{array}{l}\text { EGSnrc, MCNPX 2.5, MCNPX 2.6-CEM, GEANT4, } \\
\text { PHITS, FLUKA }\end{array}$ \\
\hline
\end{tabular}

on the recommendation of ICRP 103 (2007). Unlike ICRP 74 (1996) and past publications, ICRP 116 (2010) provided dose conversion coefficients that utilized the same computational phantoms for the type of radiation and irradiation exposure geometry, allowing many research groups to evaluate the values. However, the Monte Carlo radiation transport codes (i.e., EGSnrc, FLUKA, GEANT4, MCNPX, and PHITS) used were diverse. The conversion coefficient needed to calculate the effective dose from radiation fluence was derived using tissue dose conversion coefficients, a radiation weighting factor, and a tissue weighting factor, as provided in the recommendation of ICRP 103 (2007). To calculate the dose conversion coefficient, a vacuum outside of the phantoms and whole body exposure were assumed, and a unidirectional wide beam with the irradiation exposure geometry shown in Table 2 was applied.

\section{Models and data applied for evaluating the dose (conversion) coefficient of the ICRP}

1) Radiation and tissue weighting factors

The first radiation dose that was used after considering the relative biological effectiveness (RBE) of different types of radiation was the RBE dose in rem units as advised in the 1956 ICRU recommendations. The rem unit is the sum of absorbed doses, given in rad units, after the RBE weighting. This dose was replaced with the dose equivalent by the ICRU and ICRP, where the dose equivalent was defined as a multiple of the absorbed dose, the radiation quality factor, the dose distribution factor, and other required correction fac- tors (ICRU 1962).

The ICRP introduced a new dose equivalent, known as the effective dose equivalent, in the ICRP 26 recommendations to manage the stochastic effect. This quantity was defined as a weighted sum of the dose equivalents for various tissues and organs of the human body, where the weight factor was defined as the tissue weighting factor. At the same time, an SI unit for the dose was chosen, with grays (Gy) for rad and Sievert (Sv) for rem (100 rad = 1 Gy, 100 rem = 1 Sv) [3].

The definition and calculation methods for the human body dose were modified in the ICRP 60 recommendations. For the purpose of radiological protection, the base dose was defined as the averaged absorbed dose for all tissues and organs. In addition, considering that biological effect of radiation does not simply reflect linear energy transfer (LET), it was decided in the ICRP 60 recommendation to use the radiation weighting factor, which was evaluated based on RBE considering the stochastic effect at low doses, in place of the quality factor used to calculate dose equivalents. To differentiate this value from the existing dose equivalent and effective dose equivalents, it was redefined as the equivalent dose and effective dose. Some of the tissue weighting factors were also modified to reflect new findings regarding the health effects of radiation [4].

2) Reference man

In order to implement comprehensive and reproducible radiological protection guidance, it is important to use a consistent standard value that can clearly describe anatomical 
and physiological characteristics [12]. The first reference man that was established by the ICRP for dose assessments was the standard man in ICRP 2 . This was followed by the ICRP 23 (1975) reference man, and the ICRP 89 (2002) reference individual.

The standard man in ICRP 2 (1959) was designed to represent a typical adult who is occupationally exposed. The details of the standard man (distribution ratio of elements that form the body and organs, weight and effective radius of the body and organs, rate of intake and excretion, and information related to the respiratory and gastrointestinal tracts) were also given in ICRP 2 (1959) [13].

To consider the impact of individual diversity regarding age, gender, and other factors that must be considered in a dose assessment on the calculations, the standard man was changed to the reference man in 1975. The belief that information should be obtained from a wide range of populations that have been exposed to various radiation sources and live in various countries and regions with distinctive geographical features won out over the opinion that a specific and detailed standard man representing a specific population group was needed. Since a wide range of characteristics were found based on racial and climactic conditions, it was concluded that the standard man should not be defined as representative of a specific population group. However, due to various practical limitations, the reference man was defined based on characteristics of the populations of Europe and the U.S. This was because the populations of Europe and the U.S. consist of relatively diverse races and because relatively more research data were available for these populations. The reference man was defined as a white man 20-30 yr of age, with a weight of $70 \mathrm{~kg}$ and a height of $170 \mathrm{~cm}$, who lives in a climate with an average temperature of $10^{\circ} \mathrm{C}-20^{\circ} \mathrm{C}$ and has North American habits and traditions. The biokinetics of the deposited radionuclides in the body and information about anatomy, morphology, and physiology related to the dose assessment are provided in ICRP 23 (1975) [14].

After ICRP 23 (1975) was published, many new findings regarding the biokinetics and dose assessment of radionuclides emerged, and as the importance of public exposure was better understood, the decision was made to modify the reference man to consider other characteristics of minority population groups (age, gender, race, and other factors affecting the dose assessment). As the ICRP 23 (1975) reference man was changed to the ICRP 89 (2002) reference individual, standard values for male and female adults along with 6 age groups (newborn; 1, 5, 10, and $15 \mathrm{yr}$; adult) were presented. Although the age range of adults in ICRP 89 (1975) is 20-50 yr old, if a specific age is required for an adult, the average age is chosen to be 35 . As with the ICRP 23 (1975), data from western Europe and North America were chosen as standard values since anatomy, composition of the body, and physiology were the best researched in those populations. ICRP 89 (2002) compared the population characteristics of some Asian countries (Japan, China, and India) with those of western Europe and North America. Although physical values of the body such as height or weight were higher in western Europe and North America, the weights of specific organs and tissues were shown to be similar to those found in Asia [12].

\section{3) Reference phantom}

A reference phantom is used for the evaluation of the equivalent dose and effective dose. Until ICRP 110 (2009) officially adopted the voxel phantom, ICRP did not have an officially recommended phantom. Simplified MIRD phantoms based on the mathematical expressions of planes, cylinders, cones, ovals, and spheres were used. These phantoms used the concept of a reference man and anatomical data presented in ICRP 23 (1975) as their foundations. ICRP began to use such standard data starting from the standard man presented in ICRP 2 (1959), with its range of data expanded by ICRP 23 (1975), followed by the inclusion of age-dependent and gender-dependent characteristics in ICRP 89 (2002).

The standard male and female voxel phantom officially adopted by ICRP 110 (2009) to replace the MIRD phantom uses medical tomographic image data of an actual human body, with around 140 organs and tissues depicted in 3D by millions of voxels. The adult subjects were chosen due to their similarity to the standards published in ICRP 89 (2002). The male model was $38 \mathrm{yr}$ old and had a height of $176 \mathrm{~cm}$, with a weight of slightly less than $70 \mathrm{~kg}$, while the female model was $43 \mathrm{yr}$ old had a height of $167 \mathrm{~cm}$, with a weight of $59 \mathrm{~kg}$. The ICRP 89 (2002) standard male was $176 \mathrm{~cm}$ in height and weighed $73 \mathrm{~kg}$, while the standard female was 163 $\mathrm{cm}$ in height and weighed $60 \mathrm{~kg}[1,15]$.

\section{4) Respiratory tract model}

The first ICRP respiratory tract model was presented in ICRP 30 (1979). This model was developed for the restriction of radionuclide intake in workers. If radioactive aerosol is inhaled, partial exposure of the respiratory tract occurs. Addi- 
tionally, exposure of other tissues and organs may occur if the inhaled radionuclide is deposited in the lungs or moves to another part of the body. The radionuclides transferred to the various parts of the respiratory tract after inhalation depend on the size distribution of the radionuclides that were inhaled. The measurements of the distribution of materials and their residues were conducted based on the report published in 1966 by the ICRP Task Group on Lung Dynamics. This model considered the size of the particles and defined the residue by separating them into 3 groups $(\mathrm{D}, \mathrm{W}$, and $\mathrm{Y}$ ) based on the chemical form of the aerosol.

In addition, the model also provides information regarding the various paths of the clearance of materials from the lung, and separates the respiratory tract into the nasal, esophageal and bronchial, and lung areas. Although the dose distribution within the tract associated with inhaled radionuclides appears extremely nonuniform, in the dose assessment for the respiratory tract in ICRP 30 (1979), the tracheobronchial region, pulmonary region, and pulmonary lymph nodes were assumed to be a 1,000-g single organ (weight of the standard man's lung as chosen in ICRP 23 [1975]), and assigned a tissue weighting factor for lung tissue (ICRP 26 [1977] recommendation) to calculate the average dose [16].

In ICRP 66 (1994), instead of developing an entirely new respiratory tract model, the ICRP 30 lung model for workers was modified. The reasons behind the modification were increases in knowledge regarding the anatomy, physiology, deposition and removal of the inhaled radioactive particles, and biological effects, as well as the broader range of demands regarding dose assessments. This model did not go into detail beyond the point that was necessary for dose assessment and was designed to be applicable to all members of the global population. The ICRP 66 (1994) model considered anatomy, cytology, physiology, radiobiology, and the deposition and removal of aerosols and divided the tract into 4 major areas (extrathoracic region [ET], bronchial region [BB], bronchiolar region $[\mathrm{bb}]$, and alveolar-interstitial region $[\mathrm{AI}])$.

For dose assessments, the morphology and cytological size of such respiratory tract area were based on the standard worker, and the sizes were modified to be applied to members of the public (newborn; 1, 5, and $10 \mathrm{yr}$ old; adults). Information regarding size was used to define the mass of the tissue containing the radiosensitive cells for each region under evaluation. The previous ICRP 30 (1979) lung model calculated the average dosage using the tissue weighting factor of the lungs by assuming that the entire respiratory tract was one organ, despite the nonuniform dose distribution within the tract and the variance in sensitivity for each type of tissue. This was corrected in the ICRP 66 (1994) respiratory tract model by evaluating the dosage for each of the 6 tissues (ET1, ET2, BB, bb, AI, LNTH, and LNET) that are exposed to the inhaled radioactive material. The existing calculation procedure provided in ICRP 30 (1979), ICRP 56 (1989), which improved the ICRP 30 dose assessment equation by taking into account age dependency, and the newly developed calculation procedure provided in ICRP 60 (1991) recommendations were applied in order to evaluate the dose for the respiratory tract tissues [7].

\section{5) Gastrointestinal tract model}

The first ICRP gastrointestinal tract model was the ICRP 30 (1979) model, which was developed to calculate the occupational exposure dose caused by direct intake by extending the effect of inhaled radionuclides from the respiratory tract to the gastrointestinal tract. In the ICRP 30 (1979) gastrointestinal tract model, the gastrointestinal tract was divided into 4 compartments (stomach, small intestine, and upper and lower large intestine) to describe the transportation of consumed material within the tract. It was assumed that the absorption of materials through blood only occurred in the small intestine. The transfer coefficient $(\lambda)$ regarding the transportation of intestinal materials was defined as the inverse of the average residence time. The average residence time for each compartment was given in ICRP 30 (1979). It was assumed that the transportation of materials from one compartment to another is governed by first-order dynamics. Exposure was quantified with respect to the 4 compartments of the gastrointestinal tract and the mucosa of each of the compartments.

Although the ICRP 30 (1979) gastrointestinal tract model was developed for dose calculation for the occupational exposure of an adult, it was also used for the age-dependent dose coefficient for members of the public in ICRP 56 (1989), 67 (1993), 69 (1995), 71 (1995), and 72 (1996). To take into consideration that the gastrointestinal tract of a child has less mass than that of an adult, the size of the model in ICRP 30 (1979) was modified to calculate a coefficient for newborns and children. Although the high absorption rate of radionuclides within the gastrointestinal tract of a newborn was considered, the difference in transition time between the regions of the gastrointestinal tract was not considered. To replace this ICRP 30 (1979) model, ICRP 100 (2006) provided a new 
model (human alimentary tract model) that was applicable to all radionuclide intake scenarios for children and adults. The ICRP 100 (2006) gastrointestinal tract model contains all parts of the digestive system, utilizes the tissue weighting factors outlined in ICRP 60 (1991), and calculates values based on all cells sensitive to radiation within the gastrointestinal tract (including the oral cavity, esophagus, stomach, small intestine, left and right colon, rectum, and sigmoid colon). Variables dependent on age and gender, such as the size of the tissue and transition time of materials between the different regions of the gastrointestinal tract were also provided. The absorption of radionuclides through blood was typically assumed to only take place in the small intestine, but when usable data existed, it was possible to characterize the absorption and residue of radionuclides in areas other than the small intestine [17].

\section{6) Nuclide decay data}

ICRP 38 (1983) provides radionuclide transformation and decay data for radionuclides in ICRP 30, Parts 1-3 and Supplements to Parts 1-3, and the radionuclides of interest in nuclear medicine (a total of 820 radionuclides: 764 nuclides with half-lives greater than $10 \mathrm{~min}$, and 56 nuclides with halflives less than $10 \mathrm{~min}$ ). The various radiation intensities and energies of each of the radionuclides are presented in the form of a table. This information was calculated using the basic nuclear decay data in the Evaluated Nuclear Structure Data Files (ENSDF) as the input data for the EDISTR calculation code. The ENSDF data are a part of the database developed and maintained by the Oak Ridge National Laboratory Nuclear Data Project [18].

ICRP 107 (2008) provides a database of physical data required for the calculation of protective quantities and operational quantities of each radionuclide. This database replaced the ICRP 38 (1983) data, and is used to calculate the dose coefficient for exposure or intake of radionuclides in a wide range of environments. The database contains information regarding the intensity and energy of radiation emitted from the nuclear transformation, half-life, and decay chains of 1252 radionuclides from 97 elements. It contains information on 922 radionuclides with half-lives of greater than 10 minutes and 330 radionuclides with half-lives of less than 10 minutes in 5 data files. These files can be electronically accessed on the $\mathrm{CD}$ that is provided along with the ICRP 107 (2008) [19].

\section{Federal guidance for radiological protection}

The Federal Radiation Council (FRC) was established to advise the president regarding federal policies regarding radioactive materials that have health effects on the public, and was also the first to present federal radiological protection guidance. The council published a series of guidelines starting with the first federal radiological protection guidance documents published in 1960, which contained the basic concepts of protection of the public and workers. The guidance was strongly influenced by the ICRP and NCRP recommendations and hence was consistent with those recommendations. As the FRC was dissolved in 1970, its job was transferred to the newly formed EPA. Starting from the mid1980s, the EPA has published a series of Federal Guidance documents to provide technical information to federal agencies in support of radiological protection programs.

The first report was FGR 10 (1984), which contained the derived concentration of radioactivity in the air and water for the annual dose limit advised for workers in the 1960s. This report was replaced by FGR 11, which was published in 1988. FGR 11 (1988) contained updated dose coefficients for the internal exposure of members of the public and limits on intake and air concentration limits for the implementation of the Radiation Protection Guidance for Occupational Exposure, which was a Presidential Guidance publication in 1987. FGR 12 (1993) contained the dose coefficient for external exposure from radionuclides in the air, water, and soil. FGR 13 (1999) contained numerous factors that were used in the evaluation of cancer risk from low-level radiation from various radionuclides and provided updated internal dose coefficients through the FGR 13 CD supplement $[2,20,21]$.

\section{FGR dose coefficient}

FGR dose coefficients for members of the public and workers were provided in FGR 11 (1988), 12 (1993), and 13 (1999). The summarized organization of the background for the dose coefficient derivation, assumptions, applied model, and data used in the calculation are shown in Table 3. As shown in Table 3, the FGR dose coefficients were evaluated on the basis of the ICRP main recommendations, ICRP respiratory and gastrointestinal tract models, the ICRP biokinetic model and data, and the ICRP nuclide decay data. The main difference between the FGR dose assessment system and the ICRP dose assessment system is that the FGR system established a standard man using U.S. population data $[2,20$, 21]. Since the FGR and ICRP coefficient evaluation systems 
Table 3. Summary of Applied Models and Data for Calculating Dose Conversion Coefficients in FGR 11 (1988), 12 (1993), and 13 (1999) $[2,20,21]$

\begin{tabular}{lccc}
\hline & FGR 11 (1988) & FGR 12 (1993) & FGR 13 (1999) \\
\hline ICRP recommendation & ICRP 26 & ICRP 26 & ICRP 60 \\
$\begin{array}{l}\text { Gastrointestinal tract } \\
\text { model }\end{array}$ & ICRP 30 & $-^{*}$ & ICRP 30 \\
Respiratory tract model & ICRP 30 & - & ICRP 66 \\
Nuclear decay data & ICRP 38 & ICRP 38 & ICRP 38 \\
Internal dose coefficients & + & - & + \\
External dose coefficients & - & + & - \\
\hline
\end{tabular}

${ }^{*}+/-$, dose coefficients given/not given in report.

were developed under the same context, the applied model and data used in the evaluation are mostly the same. Hence, detailed information regarding this has been omitted in this section, and information is only presented regarding the ICRP publications that contained the models used in the FGR dose assessment.

\section{1) FGR 11 (1988)}

FGR 11 (1988) provided information for the establishment of a regulation to manage the derived air concentrations and annual limits on intake for ingested and inhaled radionuclides in a workplace or an environment in which air submersion could lead to exposure to radionuclides. It also outlined the dose coefficients for exposure that are typically used for the evaluation of the average individual committed dose for a member of the public with characteristics similar to those of the standard man.

Furthermore, it also provided the dose equivalent coefficients and effective dose equivalent coefficients for inhalation and ingestion for more than 800 radionuclides, and also provided dose equivalent coefficients and effective dose equivalent coefficients for external exposure (submersion) in the air. The tissue weighting factors and the radiation quality factors from ICRP 26 (1977) were used for the evaluation of the dose equivalent coefficients and effective dose equivalent coefficients on organs and tissues for each radionuclide. The organs and tissues that were evaluated were the gonads, chest, lungs, red bone marrow, bone surface, thyroid, and residual tissue. As discussed before, the basic anatomical and biokinetic data from the ICRP 23 (1975) standard man were used for the dose assessment. The gastrointestinal and respiratory tract models for workers from ICRP 30 (1979) were applied. FGR 11 (1988) only presented dose coefficients for adults and did not conduct evaluations on age and gender dependency. Although it can be considered out of date since it used the old ICRP 26 (1977) model, it is still used in some regulations in the U.S. $[2,22]$.

\section{2) FGR 12 (1993)}

FGR 12 (1993) provided the dose coefficients for external exposure from photons and electrons emitted from radionuclides distributed in the air, water, and soil. Since FGR 12 (1993) was published as a sister publication to FGR 11 (1988), which provided the internal dose coefficients, the ICRP 26 (1977) radiation and tissue weighting factors used in the FGR 11 (1988) were also used in FGR 12 (1993). This was done because utilizing the updated radiation and tissue weighting factors published in ICRP 60 (1991) would have required major changes to the existing regulations in the United States; therefore, choosing to use the old ICRP 26 (1977) was inevitable.

Types of radiation that have high penetrating ability, allowing them to easily travel through human tissue, and can deposit energy on radiosensitive organs and tissues are of interest in the study of external exposure. FGR 12 (1993) only considered photons, including Bremsstrahlung, and electrons. The radiation dose depends heavily on the temporal and spatial distribution on the person who is exposed. The external exposure situations that FGR 12 (1993) considered were air submersion, water immersion, and ground exposure. The calculation of the exposure dose on the human body from randomly distributed radionuclides in the environment involves complicated processes. As a result, FGR 12 (1993) calculated the external exposure dose coefficients by considering simplified and idealized irradiation exposure geometries (constant radionuclide concentration from the position of the exposed individual, and infinite or half-infinite contaminated media [contaminated air, water, or soil]). In the evaluation, the standard man was an adult $179 \mathrm{~cm}$ in height who weighed $73 \mathrm{~kg}$ (a different standard man from ICRP), and the ICRP reference man data ICRP 23 [1975]) were used along with the Monte Carlo method. FGR 12 (1993) provided external dose coefficients for the 825 radionuclides included in ICRP 38 (1983).

When calculating the external exposure dose from such dose coefficients, the FGR recommends that correction factors be used for each situation to make more a realistic assessment of the exposed individuals. Age-dependent and gender-dependent external exposure dose coefficients for around 1200 radionuclides are being developed in the Oak Ridge National Laboratory following the ICRP 103 (2007) recommendations and the ICRP 107 (2008) radionuclide de- 
cay data, and are planned to be published in FGR 15 [22, 23].

\section{3) FGR 13 (1999)}

FGR 13 (1999) presented many factors used to evaluate the potential cancer risk due to low-level exposure to radionuclides. The most recent models and approaches were used to consider the age and gender dependency of cause of death, risk from radiation, dose assessment, metabolism, and intake in the human body in the calculation of the risk from internal and external exposure. The risk coefficient of an individual who is exposed to radionuclides from the environment is the probability of cancer incidence or cancer death per time-integrated radioactivity from the air or soil for external exposure or per unit radioactivity inhaled or ingested for internal exposure.

The risk coefficient can be interpreted as the average risk per unit exposure of both a person who has been exposed to a constant concentration of radionuclides in the environment over a lifetime or a person who has been exposed for a short period. As an average risk coefficient, based on the age and gender distributions of a hypothetical steady population with a survival function and cancer death rate corresponding to the most recent data at the time, the risk coefficient in FGR 13 (1999) could be applied to all members of the public. In the FGR 13 version that was updated in 2002, the new Biological Effects of Ionizing Radiation (BEIR) VII scientific data were applied. With few exceptions, the radionuclides considered in the external exposure scenario were the same as were considered in FGR 12 (1993), and the internal exposure scenario was the same as that considered in ICRP 72 (1996) [21].

The CD supplement for FGR 13 was also distributed in 2002, and included all the data files and dose coefficient databases used in the risk coefficient calculation in FGR 13 (1999). The age-specific dose coefficient provided in the CD supplement used ICRP 60 (1991) as its basis and was evaluated on average for both genders, with the respiratory tract model in ICRP 66 (1994) used to replace the dose coefficients from FGR 11 (1988). However, the basis of radiological protection is still FGR 11 (1988). The CD supplement also contained the FGR 12 (1993) external exposure dose coefficients. The existing FGR 12 (1993) dose coefficients were evaluated on the basis of the ICRP 26 (1977) recommendations, but the $\mathrm{CD}$ that was distributed updated the values to reflect the effective dose values defined in the ICRP 60 (1991) [22].

Age-dependent and gender-dependent cancer risk coefficients based on the UN Scientific Committee on the Effects of Atomic Radiation (UNSCEAR) and BEIR VII data, and the ICRP 103 (2007) recommendations are currently in development and are planned to be released in FGR 16. Age-dependent and gender-dependent internal exposure dose coefficients based on ICRP 103 (2007) are also planned to be released in a future FGR (number undecided) technical report [23].

\section{Conclusion}

The dose conversion coefficients presented in the ICRP and FGR guidelines are generally used for dose assessments. Before applying these dose conversion coefficients, it is important to accurately understand the derivation, background, and methodology of the coefficients to use them appropriately in the assessment. Hence, in this paper, we reviewed the radiological protection and dose assessment systems of the ICRP and FGR, analyzed and organized the major publications that have been modified or will be modified, provided information regarding the dose conversion coefficients for the internal and external exposure dose assessment, and discussed the applied models and data used in the derivation of the dose (conversion) coefficients. The FGR dose assessment system was strongly influenced by the ICRP and NCRP, and is hence consistent with those recommendations. Moreover, the ICRP and FGR both used the scientific data reported by BEIR and UNSCEAR as their primary source of information. The difference between the ICRP and FGR lies in the fact that the ICRP utilized information regarding a population of diverse races, whereas the FGR utilized data on the American population, as its goal was to provide guidelines for radiological protection in the US. This paper is expected to be used as basic research material in the area of radiological protection and dose assessment.

\section{Acknowledgements}

This work was supported by the National Research Foundation of Korea (NRF) and Nuclear Safety Research Program through the Korea Foundation of Nuclear Safety (KOFONS) grant funded by the Korea government (MSIP, NSSC) and the Nuclear Safety and Security Commission (NSSC) (MSIP: NRF-2012M2A8A4025912, NRF-2015M2A2B2034282, NSSC: KORSAF-1205014-0415-SB110). 


\section{References}

1. International Commission on Radiological Protection. The 2007 recommendations of the International Commission on Radiological Protection. ICRP Publication 103. 2007;3-70.

2. Environmental Protection Agency. Limiting values of radionuclide intake and air concentration and dose conversion factors for inhalation, submersion, and ingestion. Federal Guidance Report No. 11. 1988;1-12.

3. International Commission on Radiological Protection. Recommendations of the International Commission on Radiological Protection. ICRP Publication 26. 1977;1-6.

4. International Commission on Radiological Protection. The 1990 recommendations of the International Commission on Radiological Protection. ICRP Publication 60. 1991;25-32.

5. International Commission on Radiological Protection. Age-dependent doses to members of the public from intake of radionuclides: Part 1. ICRP Publication 56. 1989;1-8.

6. International Commission on Radiological Protection. Age-dependent doses to members of the public from intake of radionuclides: Part 5. Compilation of ingestion and inhalation dose coefficients. ICRP Publication 72. 1996;5-6.

7. International Commission on Radiological Protection. Human respiratory tract model for radiological protection. ICRP Publication 66. 1994;76-83.

8. International Commission on Radiological Protection. Dose coefficients for intakes of radionuclides by workers. ICRP Publication 68. 1994;1.

9. International Commission on Radiological Protection. Compendium of dose coefficients based on ICRP Publication 60. ICRP Publication 119. 2012;7-19.

10. International Commission on Radiological Protection. Conversion coefficients for use in radiological protection against external radiation. ICRP Publication 74. 1996;24-36.

11. International Commission on Radiological Protection. Conversion coefficients for radiological protection quantities for external radiation exposures. ICRP Publication 116. 2010;13-25.
12. International Commission on Radiological Protection. Basic anatomical and physiological data for use in radiological protection. ICRP Publication 89. 2002;7-10.

13. International Commission on Radiological Protection. Permissible dose for internal radiation. ICRP Publication 2. 1959;7.

14. International Commission on Radiological Protection. Report of the task group on reference man. ICRP Publication 23. 1975;2-5.

15. International Commission on Radiological Protection. Adult reference computational phantoms. ICRP Publication 110. 2009; 29-30.

16. International Commission on Radiological Protection. Limits for the intake of radionuclides by workers. ICRP Publication 30, part 1. 1977;23-34.

17. International Commission on Radiological Protection. Human alimentary tract model for radiological protection. ICRP Publication 100. 2006;21-24.

18. International Commission on Radiological Protection. Radionuclide transformation: energy and intensity of emissions. ICRP Publication 38. 1983;1-7.

19. International Commission on Radiological Protection. Nuclear decay data for dosimetric calculation. ICRP Publication 107. 2008;3-9.

20. Environmental Protection Agency. External exposure to radionuclides in air, water, and soil. Federal Guidance Report No. 12. 1993;1-7.

21. Environmental Protection Agency. Cancer risk coefficients for environmental exposure to radionuclides. Federal Guidance Report No. 13. 1999;1-19.

22. Boyd MA. 50 years of federal radiation protection guidance What's left to do?.2015 The North Carolina Chapter of the Health Physics Society (NCHPS) Spring Meeting. Carolina beach, NC. March 5-6, 2015.

23. Boyd MA. The influence of ICRP publication 103 on current actions of the U.S. environmental protection agency. 13th International Congress of the International Radiation Protection Association. Glasgow, Scotland. May 17, 2012. 